\title{
Farsça-Türkçe Sözlük Geleneğinin Önemli Halkalarından Ferheng-i Şû̂rî’nin Neşrine Dair
}

\author{
Songül Akboğa ${ }^{1}$ (i)
}

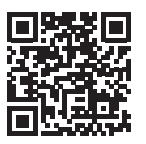

${ }^{1}$ Araştırma Görevlisi, Nevşehir Hacı Bektaş Veli Üniversitesi, Fen-Edebiyat Fakültesi, Türk Dili ve Edebiyatı Bölümü, Nevşehir, Türkiye

ORCID: S.A. 0000-0003-3153-5510

Sorumlu yazar/Corresponding author: Songül Akboğa,

Nevşehir Hacı Bektaş Veli Üniversitesi, Fen-Edebiyat Fakültesi, Türk Dili ve Edebiyatı Bölümü, Nevşehir, Türkiye

E-mail: songulakboga@nevsehir.edu.tr

Başvuru/Submitted: 03.05.2020

Kabul/Accepted: 13.11 .2020

\section{Atıf/Citation:}

Akboga, S. (2020). Farsça-Türkçe Sözlük Geleneğinin Önemli Halkalarından Ferheng-i Şuûrî’nin Neşrine Dair [Farsça-Türkçe Sözlük Geleneğinin Önemli Halkalarından Ferheng-i Şuûrî'nin Neşrine Dair]. TUDED 60(2), 795-802. https://doi.org/10.26650/TUDED2020-0029

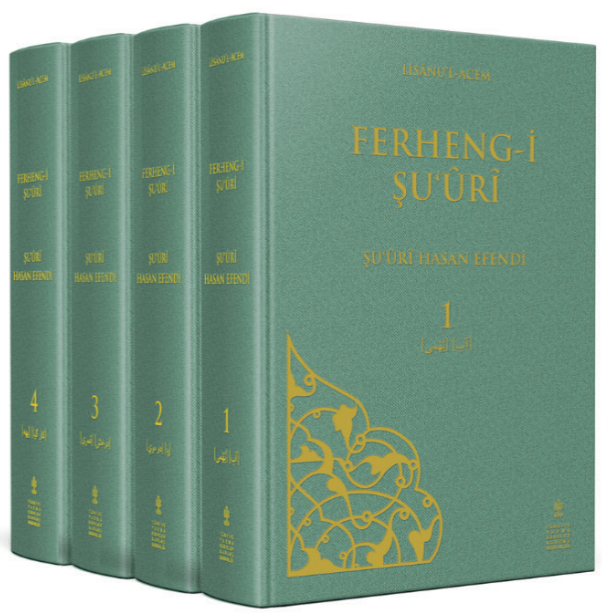


Türklerin İslamiyet'in kabulüyle birlikte yoğun bir şekilde ilişki kurduğu toplumların başında Arap ve Fars milletleri gelir. Türkistan ve İran coğrafyasında hüküm süren Gazneli ve özellikle Selçuklu Devleti dönemlerinde halkın çoğunluğunun Fars olması; bu devletlerin idari teşkilatında İranlı yöneticilere de görev verilmesi; devlet yönetimindeki Türk asıllı sultanların şairi, şiiri ve sanatkârı koruyup destekleme anlayışına sahip olmaları ve Farsça ilmî ve edebî eserlerin yazımını teşvik etmeleri Farsçanın hem halk arasında hem de devlet kademelerinde aktif bir şekilde rol almasında etkili olmuştur. Bununla birlikte Farsça şiir söyleyerek Fars edebiyatının gelişmesine katkı sağlayan Türk asıllı şairlerin varlığı ve özellikle Farslarla uzun yıllar kesintisiz olarak sürdürülen siyasi, edebî, kültürel ve toplumsal ilişkiler Farsça ve Türkçenin devamlı olarak iç içe olmasına vesile olmuş, dolayısıyla bu şartlar altında uzun yıllar birlikte yaşayan bu iki milletin dil ve edebiyatları birbirlerini etkilemiştir. ${ }^{1}$ Din, dil, coğrafya, siyaset, yönetim ve ticaret gibi konularda ortak bir paydaya sahip toplumların birbirlerinden etkilenmemeleri neredeyse imkânsız gibidir. Buna bağlı olarak birbirini etkileyen toplumlarda arı bir kültür ve edebiyattan bahsetmek de mümkün değildir.

Türk ve Fars edebiyatları arasındaki etkileşimin somut bir şekilde görülebileceği konulardan biri bu iki dil arasındaki kelime alışverişidir. Tarihî süreç içinde değerlendirildiğinde Türkçe ve Farsçanın birbirlerinden kelime alıp verme konusunda oldukça cömert olduğu görülmektedir. Birbirlerini bu derece etkileyen iki dilin söz varlığını ve anlam dünyasını ortaya koyma düşüncesi, özellikle Anadolu'da edebiyat ve şiirin icrasında lisânî ve edebî unsurlarından faydalanılan Farsçanın öğrenilmesi hususundaki mecburiyet ve eğitim kurumlarında ders olarak okutulan Fars klasiklerinin talebeler ve diğer kişilerce daha iyi anlaşılabilmesini sağlama düşüncesi Farsça-Türkçe sözlük telifi ihtiyacını da beraberinde getirmiştir. Buna paralel olarak Farsçaya ilgi duyan ve bu dili iyi bilen Osmanlı sözlükçüleri, çoğunluğu mensur olmak üzere manzum ve mensur pek çok Farsça-Türkçe sözlük kaleme almıştır. ${ }^{2}$ Bunlardan biri de 17. yüzyılda Şu'ûrî Hasan Efendi tarafindan yazılan Ferheng-i Şu ‘ûrî (Lisânu'l- 'Acem) adlı eserdir.

Eserin müellifi Şu'ûrî Hasan Efendi Halep’te doğmuştur. İstanbul'a geldikten sonra uzun yıllar divân-1 hümâyun kâtipliği yapmış, ömrünün sonlarına doğru maliyede çalışmış ve bir süre sonra da vefat etmiştir. (Ölüm tarihi kimi kaynaklarda h.1100 kimisinde de h.1105 olarak geçmektedir.) Dîvânçe, Ferheng-i Şu'ûrî, Müntehab-ı Ferheng-i Şu'ûrî, Şerh-i Pend-i 'Attâr ve Ta'dîlü'l-Emzice adlı beş eseri vardır. Bu eserler içerisinde ona asıl şöhretini kazandıran ise Ferheng-i Şu 'ûrî olmuştur (Y1lmaz, 2019, s.22-23).

Ferheng-i Şu ‘ûrî, İbn Manzûr (ö.1311) tarafından yazılmış Lisânu'l- 'Arab adlı oldukça meşhur Arapça sözlüğe nazire olarak kaleme alınmıştır. Tam on iki yıllık uzun ve meşakkatli bir mesai ile yazılarak 1092/1682 yılında tamamlanan eser, Ferheng-i Şu 'ûrî, Lisânu'l-'Acem ve Nevâlu'l-Fuzalâ olmak üzere üç farklı isimle anılmaktadır. Müellif eserin mukaddime

1 Türk-Fars ve Türkçe-Farsça ilişkileri hakkında detaylı bilgi için bkz: Kartal, A. (2016). Türk-Fars Edebî İlişkileri-Hakikate Düşen Gölge. İstanbul: Doğu Kütüphanesi Yayınları.

2 Farsça-Türkçe sözlükler hakkında daha detaylı bilgi için bkz: Öz, Y. (2016). Tarih Boyunca Farsça-Türkçe Sözlükler. Ankara: Türk Dil Kurumu Yayınları. 
kısmında eserine Ferheng-i Şu 'ûrî lakabını, isim olarak ise Lisânu'l- 'Acem'i uygun gördüğünü belirtmiş; bu ismi verme sebebi olarak da Farsça bütün kelimeleri ihtiva etmesini göstermiştir (Y1lmaz, 2019, s.27-28).

Eserin en hacimli nüshası İbrahim Müteferrika matbaasında 1 Ekim 1742 yılında basılan iki ciltlik matbu nüshadır (454+451 vr., 33 satır). Bunun dışında bu nüshadan oluşturulmuş bazı yazma nüshalar da vardır ancak çoğu müntehabât (seçmeler) niteliğindedir. Esad Efendi 32393240-3241 numaralı nüshalar, kuvvetle muhtemel müellifin müsvedde nüshalarından biridir. ${ }^{3}$

Ferheng-i Şu 'ûrî bir mukaddime, iki defter ve bir hâtimeden oluşmaktadır. Müellif, mukaddime kısmında Farsça harfleri ve bunların Farsça dilbilgisindeki yerini değerlendirmiştir. İlk defter (Defter-i Evvel) bazı Farsça deyim, atasözü vb. 1stılahların kullanımıyla ilgili anlam bilgisine ayrılırken, ikinci defter (Defter-i Sânî) alfabetik sıraya göre dizilmiş kelimelerin anlamlarından oluşmaktadır (Yılmaz, 2019, s. 35).

Şu'ûrî eserinde 22.550 madde başı kelimeye karşılık mısra, beyit, kıta, nazım, rubâî ve mesnevî başlıklı 22.450 şahit göstermiştir. 500 civarında farklı şaire ait bu şahitler Rûdekî, Firdevsî, Sa 'dî-i Şirâzî, Ömer Hayyam, Kemâl-i Hocendî , Hâfız-1 Şirâzî gibi Fars edebiyatının önde gelen isimlerinden seçilmiştir. Müellif kelimelerin anlamlarını verirken sadece Arapça ve Osmanlı Türkçesi karşılıklarını vermekle yetinmemiş, Çağatay Türkçesinden eş anlamlı kelimeleri de Ali Şîr Nevâyî ve Lutfî’ den şahit göstererek açıklamıştır. Bazı Arapça sözcüklerin şahidini ise Arap edebiyatından seçmiştir. (Y1lmaz, 2019, s. 36-37). Ferheng-i Şu 'ûrî bağlamlı ve örnekli sözlük örneklerinden olup bu sözlükler içinde de en hacimlilerinden biridir.

Şu ‘ûrî’nin, sözlüğüne aldığı kelimeleri kullandığı kaynaklarla karşılaştırarak kılı kırk yararcasına inceleyip doğruluğunu araştıran tavrı, yeri geldiğinde kendinden önce yazılmış sözlüklerde gördügü yanlışları düzeltip eleştirecek kadar bilgi birikimine sahip olması ve bunu eserine tam anlamıyla yansıtması, kelime anlamlarını açıklarken daha anlaşılır olması için ek bilgiler vererek birtakım değerlendirmelerde bulunması ve sadece madde başı kelimeleri değil şahit beyitlerde geçen bazı terkip ve ibareleri de açıklayarak yine yeri geldiğinde bir şârih kimliğine bürünmesi Ferheng-i Şu 'ûrî' ye eleştirel bir sözlük hüviyeti vermekte; ayrıca madde zenginliği ve değer bakımından da onu kendi dönemi ve sonrasında yazılan sözlüklerden farklı bir yere koymaktadir.

İbrahim Müteferrika matbaasında basılan son kitap olma özelliğini haiz bu kıymetli eser, Sakarya Üniversitesi Türk Dili ve Edebiyatı Bölümü Eski Türk Edebiyatı Anabilim Dalı öğretim üyesi Ozan Yılmaz’ın yaklaşık dört yıllık titiz ve özverili çalışmasının bir ürünü olarak Ferheng-i Şu 'ûrî (Lisânu'l- 'Acem) ismiyle Türkiye Yazma Eserler Kurumu Başkanlığı tarafından dört cilt hâlinde Aralık 2019'da basılmış ve araştırmacıların istifadesine sunulmuştur.

3 Nüshalarla ilgili detaylı bilgi için bkz: Yılmaz, O. (2019). Ferheng-i Şu 'ûrî (Lisânu'l- 'Acem)(Cilt1-4). İstanbul: Türkiye Yazma Eserler Kurumu Başkanlığı Yayınları. 
Yazarın önsözüyle başlayan çalışmanın ilk cildi Farsça-Türkçe sözlük geleneği hakkında bilgi, eserin müellifi olan Şu 'ûrî Hasan Efendi'nin hayatı, eserleri ve edebî kişiliği, Ferheng-i Şu ' $\hat{u} r \hat{\imath}$ 'ye dair bilgiler, kaynakça, metnin hazırlanmasında takip edilen yöntemler ve Ferheng-i Şu 'ûrî̀n nin yarı transkripsiyonlu bir sistemle Latin harflerine aktarılmış metninden oluşmaktadır. İkinci, üçüncü ve dördüncü ciltleri yine Ferheng-i Şu 'ûrî’nin Latin harflerine aktarılmış metninden oluşan eser toplamda 3.777 sayfadır.

Ozan Y1lmaz, "Farsça-Türkçe Sözlük Geleneği” adlı başlıkta bu sözlüklerin dönemin bir ihtiyacı doğrultusunda ortaya çıktıklarını vurgulamış ve bu ihtiyacın sebeplerini açıklayarak telif edilen başlıca manzum ve mensur Farsça-Türkçe sözlükleri sıralamıştır. Ardından eserin müellifi Şu ‘ûrî Hasan Efendi'nin hayatı ve eserleri hakkında bilgi vermiş, edebî kişiliğine dair değerlendirmelerde bulunmuş ve bazı şiirlerinden örnekler vererek müellifin şairlik yönüne de değinmiştir.

Araştırmacı, "Ferheng-i Şu 'ûrî’ye Dair” adlı başlıkta ise eserin iç ve dış özelliklerini ele almıştır. Bunlar "Eserin Adı”, "Eserin Nüshaları”, "Eserin Yazılış Sebebi”, “Eserin Kaynakları”, "Eserin Tertibi ve Kullanımı”, “Eserin Muhtevası” ve son olarak “Eserin Etkileri” başlıkları altında detaylı bir şekilde açıklanmıştır.

"Eserin Adı" başlığında sözlüğün hangi isimlerle anıldığından ve tanındığından bahseden Yılmaz, "Eserin Nüshaları” başlığı altındaysa sözlüğün nüshalarını sınıflandırarak çalışmasına esas olan nüshanın hangisi olduğunu ve bu nüshanın tercih edilme nedenini açıklamıştır. Buna göre Yılmaz, Cemal Efendi matbaasında basılan nüsha ile Süleymaniye Kütüphanesi Esad Efendi ${ }^{4}$ ve Şehit Ali Paşa Koleksiyonu'nda ${ }^{5}$ yer alan nüshaların eksik olduğunu, Şehit Ali Paşa Koleksiyonu'ndaki nüshanın da matbu nüshayla büyük oranda örtüştüğünü söylemiş ve çalışmasında tam ve muteber nüsha olduğu için Müteferrika matbaasında basılan matbu nüshayı esas aldığını ifade etmiştir. Şehit Ali Paşa nüshasında “Defter-i Evvel” kısmındaki derkenarlardan başlıkları kırmızı mürekkeple yazılan maddelerin matbu nüshada yer almamasından dolayı bu maddeleri de esas aldığı nüshaya dâhil ettiğini dile getirmiştir.

“Eserin Yazılış Sebebi” başlığı altında Şu ûrî’nin, Osmanlı sahasında iyi bir Farsça sözlüğün eksikliğini hissederek bu işe giriştiği ifade edilmiştir. Buna göre Şu'ûrî eserinde, Farsçanın tarihî sözlüklerinden yararlanıp kendinden önce ve kendi döneminde yazılmış sözlükleri inceleyerek hepsinde yer alan kelime ve anlamları birleştirmek suretiyle daha kapsamlı bir sözlük telif etme amacında olduğunu belirtmiştir.

Şu ‘ûrî’nin madde başlarını açıklarken kullandığı kaynakları bir araya getiren Yılmaz, "Eserin Kaynakları" başlığında müellifin Sürûrî-i Kâşânî'nin Mecma 'u'l-Fürs (1597) ve Hasan bin Muhammed Encûy'un Ferheng-i Cihnângîrî (1608-9) adlı lügatleri başta olmak üzere birçok farklı klasik lügatten faydalandığını bunların isimlerini sıralayarak okuyucuya iletmiştir. 
“Eserin Tertibi ve Kullanımı” başlığı ise müellifin sözlüğünü tertip etme usulü ve kelimelerin sıralanması aşamasında tercih edilen yöntemle ilgili bilgileri içermektedir. Yılmaz, "Metnin Hazırlanmasında Takip Edilen Yöntem” başlığı altında bu konuyla ilgili bilgileri ayrıntılı bir şekilde aktarmıştır.

“Eserin Muhtevası” başlığında sözlüğün kaç bölümden oluştuğunu açıklayan Yılmaz, daha sonra bu bölümlerin içeriği hakkında bilgi vermiştir. Bu bilgilerin yanı sıra müellifin bütün kelimeleri sözlüğüne dâhil etmek gibi bir iddiasının bulunduğunu, herkesçe bilinen kelimeleri dahi metne almakta tereddüt etmediğini, çünkü bu tarz kelimelerin çok katmanlı anlam yapısına sahip olabileceği ihtimalini düşündüğünü dile getirmiştir.

Yine bu bölümde Yılmaz; Şu'ûrî’nin, sözlüğünde kelime bilgisinin dışında coğrafya, tarih, astronomi, mitoloji, tıp, musiki vb. ilimlere dair bilgilere de yer verdiğini vurgulamış; devamında sözlüğün madde başı sayısını, madde başlarına verilen şahit sayısını ve bu şahitlerin hangi şairlerden seçildiğini belirterek bu bölümü sonlandırmıştır. Müellif yemek ya da tatlı isimlerinin madde başı olduğu kısımlarda bazen bunların nasıl yapıldığını tarif etmiş; ayrıca tıp ilmine ilgisi ve yeteneği olması hasebiyle çeşitli hastalıklar ve tedavileri hakkında bilgi verip bazı bitkilerin tedavide nasıl kullanıldığına dair tespitlerde bulunmuştur. Mitolojik kahramanların yer aldığı kısımlarda ise yeri geldiğinde onlarla ilgili ayrıntılı hikayeler anlatmış; halk inanışları, halk âdetleri ve uygulamalarına da yer vermiştir. Zaman zaman bazı yer isimleri ve musikide kullanılan terimler ve makamlar hakkında da bilgi veren Şu ûrî böylece sözlüğün muhtevasını olabildiğince geniş tutmuştur. Tüm bunlar, Şu ‘ûrî’nin eserinde yalnızca dil malzemesi sunmayıp Farsça ve Türkçeye ait kültürel öğelere de yer vererek kendi hüner ve bilgi birikimini göstermesi bakımından kayda değer örneklerdir.

Yazar, "Eserin Etkileri”'ni anlattığı başlıkta Ferheng-i Şu 'ûrî̀nin Mütercim Asım'ın Burhân-l Kâtı ', Pozarofçevî İbrahim'in Mecma 'u'l-Emsâl, Mehmed Salahî’nin Kâmûs-ı Osmânî ve Mehmed İzzet'in Kâmûs-ı Fârsî gibi sözlüklere kaynaklık ettiğini söylemiştir. Ayrıca ünlü sözlükbilimci Ali Ekber Dihhudâ'nın Ferheng-i Şu ‘ûrî'ye dair olumsuz eleştirilerine yer vermiş ve bu eleştirilerin doğru olmadığını objektif bir şekilde, mantıklı ve geçerli sebeplerle izah etmiştir.

Araştırmacı, eserle ilgili teorik bilgileri verdikten sonra "Kaynakça” kısmına geçmiş ve hemen ardından metnin hazırlanmasında takip edilen yolları maddeler halinde sıralamıştır. Metnin neşriyle ilgili göze çarpan hususlar ise şöyle sıralanabilir:

Metinde çeviriyazı alfabesi sadece Arapça ve Farsça kelimelerde kullanılmış, Türkçe kelimelerde ise manzum kısımlar hariç kullanılmamıştır. Ayrıca nüsha matbu olduğu için bazı Türkçe sözcük ve eklerin yazımı, yine manzum kısımlar hariç tutularak, olabildiğince günümüz imlasına yaklaştırılmıştır: tag/dağ, timür/demir, içün/için vb. Madde başları Arap harfli olarak verilmiş ve köşeli parantez içerisinde Latin harfli okunuşları gösterilmiştir. Metinde geçen bazı Arapça-Farsça kelime ve ibarelerin okunuşu da köşeli parantez içerisinde gösterilmiştir. Çağatay Türkçesine ait kelimeler ise tırnak içerisinde verilmiştir: 
سانكين [sānkīn]: Sükūn-1 nūn u yā-yı taḥtānī ve kesr-i kāf ile. Hūȳy ve ādet edinmek. Kezāā fi-Ferheng-i Cihängììi.

ساواهن [sāv-āhen]: Eğe ile demirden dökülen hurde ki 'Arabìde براده [burāde] derler. Kezā fi'l-Mecma'.

ساون [sāvin] ve ساوين [sāvīn]: Kilāhumā bi-kesri'l-vāv. Küfe (72a) dedikleri seped ki içine penbe, iplik ve mu'teber meyve korlar. Ferheng-i Cihängìrỉde eğirmeye ḥāżırlanmış penbe ma'nāsına mervīdir.
ز زدوار [jedvār]: Be-ma'nī-i cedvār ki macrūf köktür. ماه يروين [māh-pervin] dahi derler. [cedvār], mu'arrebidir. Ve zebān-1 Moğolda "māhferfîn" derler.

ز jeġār]: Fetḥ-i ġayn-1 mu'ceme ile. İki ma'nāyadır.

Evvel, be-ma'nī-i jeng ki pas ve küftür. Demirde, bakırda ve ġayrıda nemnāk yerde durmakla peydā olur. Ve ba'́̇ı toprak üzerinde dahi yeşil küf olur. Üstād Rūdekī, beyt:

Arap harfli madde başları ve ara başlıklar kırmızı renkle yazılırken izafetli yapıları birleşik yapılardan ayırmak maksadıyla da kelime aralarına kesre işareti konulmuştur. Metinde geçen eser isimleri italik yazılmış; dipnotta ayetler ile hadislerin yeri ve anlamları verilmiş ve madde başlarının köşeli parantez içerisinde gösterilen okunuşlarında Farsça imlaya bağlı kalınmıştır. Örneğin “ü” sesi yerine "u” tercih edilirken tanım kısımlarında ise Osmanlı imlası kullanılmıştır: Bulbul/bülbül, kudâm/küdâm, kulbe/külbe, huner/hüner vb.

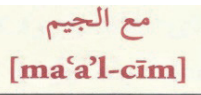

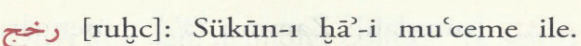
Yezd vilāyetinde bir nāhịe ismidir. Kežā fīFerheng-i Cihāngīrī.

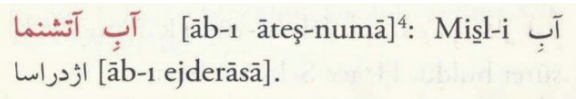

[āb be-āb nemī-resed]: Kimseden kimseye fằide yok. Hakīm Sūzenī, rubāîi:

Ozan Yılmaz’ın çalışmasını değerli kılan en önemli özelliklerden biri de Yılmaz’ın metnin Latin harflerine aktarılmasının yanı sıra tamamı 24.450 adet olan şahitlerin her birini Türkçeye tercüme etmesidir. Araştırmacı örnek olarak verilen Farsça ve Arapça şiirleri önce Arap harfleriyle göstermiş, daha sonra bunların çevirilerini parantez içinde vermiştir. Çeviriler yapılırken bunun bir sözlük metni olduğunu göz önünde bulundurarak kelime merkezli olmasına özen göstermiş ve çevirilerin sözlükte verilen anlama ve bağlama uygun olmasına dikkat etmiştir. Ayrıca Çağatay Türkçesine ait şiirlerin de dil içi çevirisini yaparak parantez içerisinde göstermiştir: 
jز [jāḡir]: Kesr-i ġayn ile. Havṣala-i murgaān ya'nī kuş kursağı. Üstād Lațîfī, beyt:

$$
\text { دائم از هينه هاى انعامش مور آز راز زاغر }
$$

(Hırs kuşunun kursağı, hep onun bağış yemleriyle beslenir.)

\section{Üstād 'Unșurī, beyt:}

$$
\text { خو از يلد از آنكه بماند ز ما ملوك زمين }
$$

(Dünya padişahları bizden kalanı yerler. Sense kursağını pislik ve murdarla doldurmaktasın.)
[آب به روي كار آورد [āb be-rūy-ı kār āverd]:

İşe șūret verdi. Mevlānā Cāmī, beyt:

$$
\begin{aligned}
& \text { تا هند خون دل خورم كو ساقئ جان يرورم }
\end{aligned}
$$

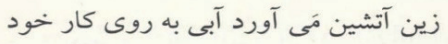

(Ne zamana dek gönül kanı içeceğim? Canıma can katan sāki hani! Şu ateş gibi kırmızı şarabı getirsin de işleri yoluna koysun.)

[āb be-rūy-1 kār āred] dahi derler. Kemāl-i Hocendī, beyt:

$$
\begin{aligned}
& \text { خاك خجند را كه ز شير از كم نهيند } \\
& \text { آرد به روزكار تو آبى به روى كار }
\end{aligned}
$$

(Şiraz’dan değersiz gördükleri Hocend toprağı -yani Kemāl-i Hocendī- senin zamanında işlerini yoluna koyuyor.)

$$
\begin{aligned}
& \text { [gum]: Nā-bedīd ve żāyi' ma'nāsınadır. } \\
& \text { Türkīde "yitik" derler. Çağatay'da } \\
& \text { "yavumak" derler. Mīr 'Alī Şīr, beyt: } \\
& \text { Çü yār köylide bolsam belā mana yavumas } \\
& \text { Bu vechle ki temürdin bolur hișār vațanım } \\
& \text { (Sevgilinin gönlünde olsam bela bana yaklaşa- } \\
& \text { maz. Zira vatanım, demirden bir kale olur.) }
\end{aligned}
$$

Ferheng-i Şu ' $\hat{u} r \hat{\imath}$ ' de neredeyse her bir madde başı için örnek verilmesi sözlüğün amacına hizmet etmesi bakımından önemlidir. Şu'ûrî yeri geldiğinde kelimeleri farklı ve bilinmeyen anlamlarına göre örneklendirmiş; onun bir madde başı için bazen birden çok şahit gösterdiği de olmuştur. Bu durum, kelimelerin anlam katmanlarını ve inceliklerini ortaya koymak, dilin geçirdiği değişimleri görmek ve dönemin söz varlığı hakkında bilgi edinmek açısından önemlidir. Eserin özellikle klasik Türk edebiyatı araştırmacılarının divan şiiri mahsullerini şerh ve tercüme faaliyetleri için önemli bir kaynak olacağ

Yılmaz, müellifin madde başını yazdıktan sonra sözcüğü oluşturan harflerin hangi harekeyle okunacağını belirttiğini söylemiştir. Çalışmasında Şu ‘ûrî'nin bu hususa dikkat edilmesini istediğini dile getiren yazar, bu kısımları aynen yazmış ve (.) ile bittikten sonra anlamı yazarak metin içinde harekesi bildirilip de okunuşu yazılmayan kelimelerin kendisi tarafindan parantez içerisinde tamamlandığını ifade etmiştir. Şu ‘ûrî’nin kelimelerin harekelendirilmesinde çok titiz davranıp her bir harfin hangi harekeyle okunacağını belirtmesi o dönemin imlâsını ve kelimelerin doğru yazılışını görmek açısından son derece önemlidir.

Araştırmacı çalışmasında matbu nüshanın varak numaralarını kullanmıştır. Böylece matbu nüshanın 1. cildindeki varak numaraları bu çalışmanın 1. ve 2. ciltlerine; 2. cildindeki varak numaraları da bu çalışmanın 3. ve 4. ciltlerine tekabül etmektedir. 1. cilt "âb-buhmâ", 2. cilt "pâ-du mûy", 3. cilt "zerahş-kumrî" ve 4. cilt de "kâr-1 giyâ-yuhe" madde başları arasını kapsamaktadır. Durâb-ı emsâl kısmı da 1. ciltte yer alır. 
Ferheng-i Şu ‘ûrî’ nin metnine geçmeden önce son olarak sözlüğün kullanımıyla ilgili bilgi veren Yılmaz, harflerin fetha, kesre ve zamme esasına göre dizildiğini belirtmiştir. Sözgelimi "be" harfinin, ilk hecesi "be-bâ" olan kelimelerle başlayıp sırasıyla "bi-bî" ve "bu-bû" olan kelimelerle devam ettiğini söyleyen yazar; fetha, kesre ve zamme sırasına göre dizilen kelimelerin son harfine de bakılması gerektiğini dile getirmiştir. Örneğin "bâbu'l-bâ'i'l-meftûha (fethalı bâ)" başlığından sonra "ma'a'l-elif (elif harfiyle birlikte)" başlığının geldiğini söyleyen Y1lmaz, bunun sözcüğün ilk hecesinin "be-bâ", son harfinin de "elif” yani “â" olduğu şeklinde yorumlanması gerektiğini belirtir. Ayrıca son harfler de elif-bâ sırasını takip eder: ma'a'l-elif, ma'a'l-bâ, ma'a’t-tâ vd. gibi. Maddelerin sıralanışında ilk ve son harflerin esas alındığg eserde Farsçanın klasik sözlüklerinde kullanılan bu metodun uygulanmasına bağlı bir kullanım zorluğu olduğu muhakkaktır. Ancak her bir cildin İçindekiler kısmında yukarıda bahsedilen bâbların sıralanması, sözlüğün daha kolay kullanılmasına olanak sağlamıştır. Sözlüğün kullanımıyla ilgili bilgiler aktarıldıktan sonra ise eserin yarı transkripsiyonlu bir şekilde Latin harflerine aktarılmış metni verilmiştir.

Ozan Yılmaz’ın her haliyle ciddi ve titiz bir çalışmanın ürünü olduğu açık olan bu çalışması özellikle Klasik Türk edebiyatında geçen anlaşılması zor Farsça kelime ve terkiplerin daha iyi anlaşılması ve yine bu kelimelerin sahip olduğu anlam katmanlarının ortaya koyulması açısından oldukça önemlidir. Örneğin eserin müellifinin "bahâr" kelimesini 14 ve "tîr" kelimesini 34 anlam üzerinden açıklaması ve bu yönüyle benzer sözlüklerden ayrılması sözü edilen düşünceyi destekler niteliktedir. Yılmaz'ın madde başı kelimeler için verilen FarsçaArapça şiirleri Türkçeye tercüme etmesi ve Çağatay Türkçesiyle yazılmış şahitlerin de dil içi çevirilerini yapması kelimelerin anlamlarının daha iyi anlaşılmasını sağlaması açısından çalışmanın değerini bir kat daha artırmaktadır. Ayrıca eserin, içerisinde barındırdığı pek çok edebî ve kültürel malzemeyle ve Farsça ile Türkçenin tarihî söz varlığını ortaya koyması hasebiyle hem Türk dili ve edebiyatı hem de Fars dili ve edebiyatı alanında çalışan araştırmacılar için önemli bir kaynak olacağı muhakkaktır.

\section{KAYNAKÇA/REFERENCES}

Kartal, A. (2016). Türk-Fars Edebî Ilişskileri-Hakikate Düssen Gölge. İstanbul: Doğu Kütüphanesi Yayınları. Öz, Y. (2016). Tarih Boyunca Farsça-Türkçe Sözlükler. Ankara: Türk Dil Kurumu Yayınları.

Yılmaz, O. (2019). Ferheng-i Şu 'ûrî (Lisânu'l- 'Acem) (Cilt 1-4). İstanbul: Türkiye Yazma Eserler Kurumu Başkanlı̆̆ Yayınları. 